\title{
Isolated transient aphasia at emergency presentation is associated with a high rate of cardioembolic embolism
}

\author{
Jason K. Wasserman, MD, PhD*§; Jeffrey J. Perry, MD, MSc ${ }^{\dagger \S}$; Dar Dowlatshahi, MD, PhD ${ }^{\ddagger \S}$; \\ Grant Stotts, MD ${ }^{\ddagger \S}$; Marco L. A. Sivilotti, MD, MSc ${ }^{\text {Tl; }}$ Andrew Worster, MD**; Marcel Emond, MD, MSc ${ }^{\dagger+}$; \\ Jane Sutherland, $\mathrm{MEd}^{\dagger \S}$; Ian G. Stiell, MD, MSc ${ }^{\dagger \S}$; Mukul Sharma, MD, $\mathrm{MSc}^{\ddagger \ddagger}$
}

\section{ABSTRACT}

Objective: A cardiac source is often implicated in strokes where the deficit includes aphasia. However, less is known about the etiology of isolated aphasia during transient ischemic attack (TIA). Our objective was to determine whether patients with isolated aphasia are likely to have a cardioembolic etiology for their TIA. Methods: We prospectively studied a cohort of TIA patients in eight tertiary-care emergency departments. Patients with isolated aphasia were identified by the treating physician at the time of emergency department presentation. Patients with dysarthria (i.e., a phonation disturbance) were not included. Potential cardiac sources for embolism were defined as atrial fibrillation on history, electrocardiogram, Holter monitor, atrial fibrillation on echocardiography, or thrombus on echocardiography.

Results: Of the 2,360 TIA patients identified, 1,155 had neurological deficits at the time of the emergency physician assessment and were included in this analysis, and 41 had isolated aphasia as their only neurological deficit. Patients with isolated aphasia were older $(73.9 \pm 10.0$ v. $67.2 \pm 14.5$ years; $p=0.003$ ), more likely to have a history of heart failure $(9.8 \%$ v. $2.6 \% ; p=0.027)$, and were twice as likely to have any cardiac source of embolism (22.0\% v. $10.6 \% ; p=0.037$ ).

Conclusions: Isolated aphasia is associated with a high rate of cardioembolic sources of embolism after TIA. Emergency patients with isolated aphasia diagnosed with a TIA warrant a rapid and thorough assessment for a cardioembolic source.

\section{RÉSUMÉ}

Objectif: L'origine cardiaque est souvent incriminée dans les accidents vasculaires cérébraux dans lesquels le déficit neurologique comprend de l'aphasie. Cependant, on connaît peu de choses sur la cause de l'aphasie isolée durant les accidents ischémiques transitoires (AIT). L'étude visait donc à déterminer si les patients atteints $d$ 'aphasie isolée étaient plus susceptibles de subir un AIT d'origine cardioembolique. Méthode: II s'agit d'une étude prospective de cohortes, composées de patients qui ont subi un AIT et qui ont été examinés dans 8 services d'urgence (SU) de soins tertiaires. Ceux qui présentaient des signes d'aphasie isolée étaient reconnus par le médecin traitant au moment de la consultation au SU. Les malades souffrant de dysarthrie (c'est-à-dire de troubles de la phonation) ont été écartés. Les sources possibles d'embolie d'origine cardiaque comprenaient la mention d'antécédents de fibrillation auriculaire (FA) à l'anamnèse; la présence de FA à l'électrocardiographie, à l'enregistrement de Holter ou à l'échocardiographie; ou encore la présence de thrombus à l'échocardiographie.

Résultats: Sur 2360 patients qui avaient subi un AIT, 1155 présentaient un déficit neurologique au moment de l'évaluation par l'urgentologue et ont été sélectionnés aux fins de I'analyse; parmi ceux-ci, 41 avaient comme seul déficit neurologique de l'aphasie isolée. Les patients atteints d'aphasie isolée étaient plus âgés que ceux qui étaient épargnés $(73,9 \pm 10,0$ contre [c.] $67,2 \pm 14,5$ ans; $p=0,003)$; ils étaient également plus susceptibles d'avoir des antécédents d'insuffisance cardiaque $(9,8 \%$ c. $2,6 \% ; p=0,027)$ et ils connaissaient deux fois plus de risques de subir un accident embolique d'origine cardiaque $(22,0 \%$ c. $10,6 \% ; p=0,037)$. Conclusions: L'aphasie isolée est associée à un taux élevé d'embolie d'origine cardiaque à la suite d'un AIT. Aussi les patients examinés au SU pour de l'aphasie isolée chez qui un diagnostic d'AIT a été posé devraient-ils faire rapidement l'objet d'une évaluation complète à la recherche de causes cardioemboliques.

From the *Department of Laboratory Medicine; †Department of Emergency Medicine; ¥Division of Neurology, Department of Medicine, The Ottawa Hospital, University of Ottawa, Ottawa, ON; §Ottawa Hospital Research Institute, University of Ottawa, Ottawa, ON; ףDepartment of Emergency Medicine, Queen's University, Kingston, ON; **Department of Medicine, McMaster University, Hamilton, ON; †tUnité de Traumatologie-urgence-soins Intensifs, Center de Recherche du CHA (Hôpital de I'Enfant-Jésus), Laval University, Quebec, QC; and ¥¥Population Health Research Institute, McMaster University, Hamilton, ON.

Presentations: Presented at the Canadian Association of Emergency Physicians Annual Scientific Meeting, Newfoundland, Canada, June 2011 and at the International Stroke Conference, Los Angeles, CA, February 9-11, 2011.

Correspondence to: Dr. Jeffrey J. Perry, Clinical Epidemiology Unit, F647, The Ottawa Hospital, 1053 Carling Avenue, Ottawa, ON K1Y 4E9; Email: jperry@ohri.ca 
Keywords: atrial fibrillation, cardioembolism, isolated aphasia, risk, stroke, transient ischemic attack

\section{INTRODUCTION}

Cardiac emboli account for $20 \%$ of all ischemic strokes, with atrial fibrillation being the most important cause of cardioembolism. ${ }^{1,2}$ Previous studies have shown that strokes resulting in cortical deficits (i.e., visual field abnormalities, neglect, aphasia) are strongly associated with a potential cardiac source of embolism. ${ }^{3,4}$ Language deficits are the most common type of higher cortical deficit to occur after acute stroke, and the finding of aphasia appears to be particularly specific for cardioembolism. ${ }^{4,5}$ Indeed, most strokes resulting in aphasia are caused by an embolism of cardiac origin. ${ }^{6-8}$ It is unclear whether the same is true for isolated aphasia during transient ischemic attack (TIA).

Strokes of cardioembolic origin also have a high rate of recurrence, as do TIAs, which have a $10 \%$ risk of stroke at 90 days, with half of these events occurring within 48 hours. $^{9-11}$ As such, cardioembolism provides an important and time-sensitive opportunity for secondary stroke prevention. At present, the immediate risk of stroke after a TIA characterized by isolated language disturbance is not well known.

Among patients diagnosed in the emergency department with TIA, we hypothesized that patients presenting with isolated aphasia would be more likely to have a cardiac source of embolism. We also hypothesized that such patients with isolated aphasia would have a higher short-term risk of stroke.

\section{METHODS}

\section{Study design and setting}

This study is a secondary analysis of a larger, prospective cohort study conducted at eight Canadian emergency departments as part of the derivation of a clinical decision rule to predict imminent stroke. ${ }^{12}$ Ethics board approval was obtained at all participating sites. The combined annual census at all participating sites was 394,000 visits.

\section{Selection of participants}

We prospectively enrolled adult patients with a final emergency department diagnosis of TIA between October 2006 and April 2010. Details regarding patient selection and data collection for this population have been previously described. ${ }^{12}$ Patients were excluded for 1) neurological deficit $>24$ hours at presentation, 2) decreased level of consciousness (i.e., Glasgow Coma Scale score of $<15$ ), 3) obvious alternate cause for the deficit other than TIA (e.g., hypoglycemia, seizure, electrolyte imbalance, migraine), 4) receiving tissue plasminogen activator, or 5) presentation to the enrolling emergency department $>7$ days after TIA. The diagnosis of TIA was defined using the World Health Organization definition: a sudden, focal neurological deficit lasting for less than 24 hours, presumed to be of vascular origin, and confined to an area of the brain or eye perfused by a specific artery. A standardized data collection form was completed by the emergency physician at the time of presentation, and the following information was prospectively collected: 1) the history of neurological symptoms, 2) physical findings, 3) electrocardiogram results, and 4) past medical history. For this study, only patients with persistent deficits at the time of presentation were included.

\section{Identification of patients with isolated aphasia}

Treating physicians were explicitly asked to identify the presence or absence of language disturbance on the history section of the study data form, and of speech difficulty on the physical examination section. When speech difficulty was identified, physicians were then asked to characterize this as aphasia or dysartbria, and with the explicit definition (aphasia = loss of ability to use written/ oral language; dysartbria = difficulty articulating) appearing next to the item on the form. For the current study, we defined isolated aphasia to be those in whom the language deficit was the only neurological deficit identified on physical examination, whether expressive or receptive. The patient complaint of language disturbance on history was insufficient to classify the patient as having aphasia for the purposes of this study. Accordingly, individuals demonstrating normal language comprehension and expression at the time of initial examination by physician were not deemed to be aphasic.

\section{Outcome and outcome assessment}

The primary outcome for this analysis was the identification of a potential cardioembolic source for the TIA. Potential cardiac sources for embolism were defined as either a previous diagnosis of atrial fibrillation; atrial 
fibrillation identified by electrocardiogram, Holter monitor, or echocardiography; or thrombus seen at echocardiography. Secondary outcomes were the occurrence of stroke at 2, 7, 30, and 90 days. All participants were followed using medical record review and a validated, standardized telephone questionnaire. ${ }^{13}$ Potential subsequent strokes identified in follow-up were adjudicated by a panel blinded to the initial presentation, unless the subsequent stroke was diagnosed by the treating neurologist, in which case it was automatically deemed an outcome event.

\section{INVESTIGATIONS}

As part of routine clinical care, all patients had an electrocardiogram performed at the index visit in the emergency department, and most were referred to a dedicated stroke clinic where they generally received the existing standard of care, the details of which have been described previously. ${ }^{14}$ Forty-eight-hour Holter monitoring and echocardiography were arranged at either the index visit or subsequently through the stroke clinic and were performed on an outpatient basis.

\section{Statistical analysis}

Data were collected and analysed in SPSS 17 (SPSS Inc., Chicago, IL). Proportions were compared using Fisher's exact test with confidence intervals (CIs) reported at $95 \%$. Continuous data are presented as mean \pm standard deviation (SD) where applicable. All tests were two-sided, and results were considered significant if $p<0.05$.

\section{RESULTS}

A total of 2,360 TIA patients were enrolled in the study, and 1,155 patients diagnosed as having a TIA presented with deficits and were included in the final analysis. Of these patients, 41 were classified as having isolated aphasia at the time of presentation (Figure 1). Patients with isolated aphasia were older $(73.9 \pm 10.0 \mathrm{v}$. $67.2 \pm 14.5$ years; $p=0.003)$ and were more likely to have a history of heart failure $(9.8 \%$ v. $2.6 \% ; p=0.027)$ (Table 1).

The investigations used to identify potential cardiac sources of embolism are shown in Table 2. Patients with isolated aphasia were twice as likely to have any cardiac source of embolism $(22.0 \%$ v. $10.6 \%$;

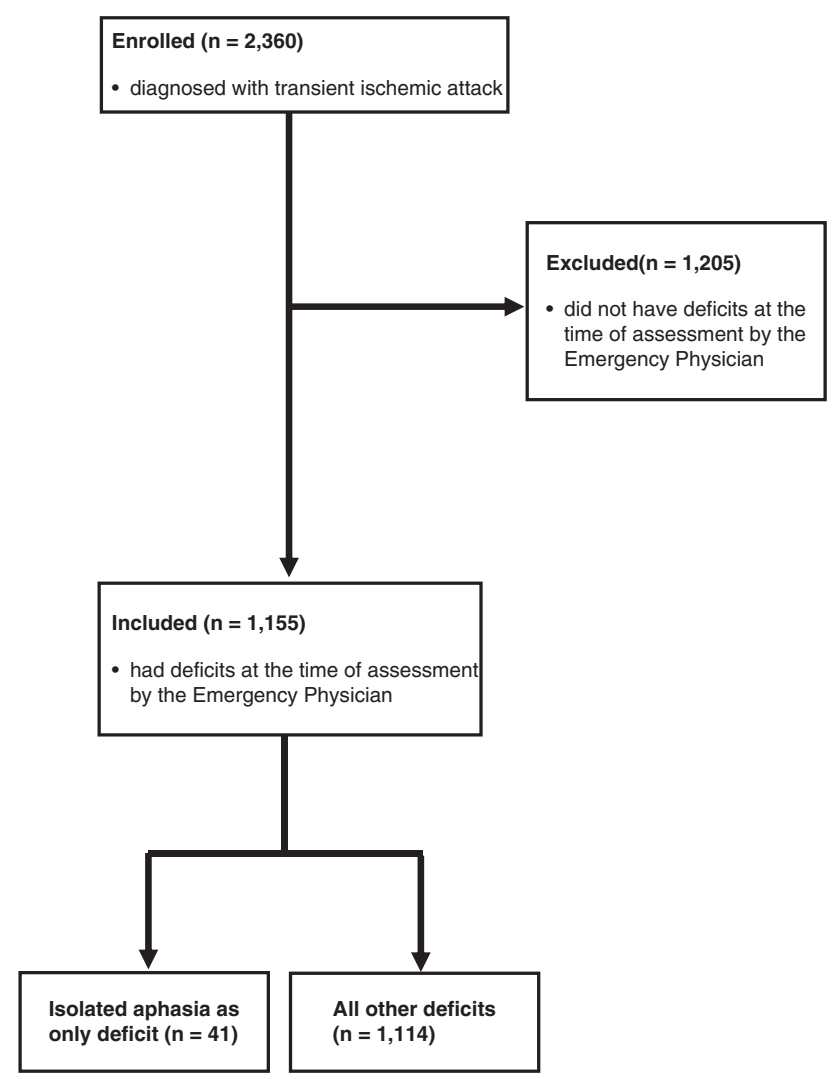

Figure 1. Patient flow.

$p=0.037)$. Specifically, patients with isolated aphasia were more likely than patients without isolated aphasia to have atrial fibrillation identified on electrocardiogram $(12.2 \%$ v. $4.3 \% ; p=0.036)$ or Holter monitor $(4.9 \%$ v. $0.7 \% ; p=0.046)$. The average delay from presentation to investigation was $27.1 \pm 21.1$ days for Holter monitor and $13.1 \pm 14.4$ days for echocardiography. All electrocardiograms were performed at the time of presentation.

The overall stroke rate in the study cohort at 2, 7, 30, and 90 days was $1.7 \%$ (CI $1.1 \%$ to $2.7 \%$ ), $2.5 \%$ (CI $1.7 \%$ to $3.6 \%$ ), $3.2 \%$ (CI $2.3 \%$ to $4.4 \%$ ), and $3.9 \%$ (CI $2.9 \%$ to $5.2 \%)$, respectively. A comparison of the stroke rate between patients with and without isolated aphasia is shown in Table 3. Patients with isolated aphasia had a higher rate of stroke than patients without isolated aphasia at 2 days, although the differences between the two groups were not significant.

\section{DISCUSSION}

In this prospective cohort study, we demonstrated that TIA patients presenting with isolated aphasia have twice 
Table 1. Patient Characteristics of Transient Ischemic Attack Patients with Neurological Deficits at the Time of Emergency Physician Assessment

\begin{tabular}{|c|c|c|c|}
\hline & Isolated Aphasia (\%) N = 41 & All Other Deficits (\%) $N=1,114$ & $p$-value \\
\hline Age, in years & $73.9 \pm 10.0$ & $67.2 \pm 14.5$ & 0.003 \\
\hline Male & $17(41.5)$ & $547(49.1)$ & 0.27 \\
\hline Systolic blood pressure, in $\mathrm{mmHg}$ & $158.1 \pm 26.1$ & $156.4 \pm 26.2$ & 0.69 \\
\hline Diastolic blood pressure, in $\mathrm{mmHg}$ & $79.3 \pm 14.5$ & $83.0 \pm 14.3$ & 0.10 \\
\hline First known transient ischemic attack & $26(63.4)$ & $687(61.7)$ & 0.87 \\
\hline Admitted to hospital & $5(12.2)$ & $73(6.6)$ & 0.19 \\
\hline \multicolumn{4}{|l|}{ Duration of symptoms } \\
\hline$<10 \min$ & $0(0)$ & $26(2.3)$ & \\
\hline $10-59 \min$ & $5(12.2)$ & $133(11.9)$ & 0.61 \\
\hline$\geq 60 \mathrm{~min}$ & $36(87.8)$ & $954(85.6)$ & \\
\hline \multicolumn{4}{|l|}{ Clinical characteristics } \\
\hline Unilateral weakness & $0(0)$ & $383(34.4)$ & $<0.001$ \\
\hline Speech disturbance & $41(100)$ & $236(21.2)$ & $<0.001$ \\
\hline Sensory disturbance & $0(0)$ & $262(23.5)$ & $<0.001$ \\
\hline Visual loss & $0(0)$ & $97(8.7)$ & $<0.001$ \\
\hline \multicolumn{4}{|l|}{ Past medical history } \\
\hline Hypertension & $30(73.2)$ & $672(60.3)$ & 0.10 \\
\hline Coronary artery disease & $13(31.7)$ & $228(20.5)$ & 0.11 \\
\hline Atrial fibrillation & $6(14.6)$ & $97(8.7)$ & 0.26 \\
\hline Heart failure & $4(9.8)$ & $29(2.6)$ & 0.027 \\
\hline Diabetes & $8(19.5)$ & $223(20.0)$ & 1.00 \\
\hline Stroke & $8(19.5)$ & $165(14.8)$ & 0.38 \\
\hline Dyslipidemia & $18(43.9)$ & $358(32.1)$ & 0.13 \\
\hline
\end{tabular}

Table 2. Potential Cardiac Sources of Embolism

\begin{tabular}{lccc} 
& $\begin{array}{c}\text { Isolated Aphasia } \\
\text { (\%) } \mathrm{N}=41\end{array}$ & $\begin{array}{c}\text { All Other Deficits } \\
\text { (\%) } \mathrm{N}=1,114\end{array}$ & p-value \\
\hline $\begin{array}{l}\text { History of atrial } \\
\text { fibrillation }\end{array}$ & $6(14.6)$ & $97(8.7)$ & 0.26 \\
$\begin{array}{c}\text { ECG atrial } \\
\text { fibrillation } \\
\text { Holter atrial } \\
\text { fibrillation }\end{array}$ & $5(12.2)$ & $48(4.3)$ & 0.036 \\
$\begin{array}{c}\text { Echo thrombus or } \\
\text { atrial fibrillation }\end{array}$ & $2(4.9)$ & $8(0.7)$ & 0.046 \\
$\begin{array}{c}\text { Any cardiac } \\
\text { source }\end{array}$ & $9(22.0)$ & $118(10.6)$ & 0.037 \\
\end{tabular}

the rate of potential cardiac sources of embolism than patients with other forms of TIA. Patients with transient isolated aphasia were also more likely to have a stroke in the next 90 days, although this difference did not reach statistical significance. Accordingly, the finding of isolated aphasia on physical examination may allow the physician to rapidly identify patients with a potential cardiac source of embolism who are also at increased risk of stroke.

\begin{tabular}{|c|c|c|}
\hline & $\begin{array}{l}\text { Isolated Aphasia }(95 \% \mathrm{Cl}) \\
\qquad \mathrm{N}=41\end{array}$ & $\begin{array}{l}\text { All Other Deficits (95\% Cl) } \\
\qquad N=1,114\end{array}$ \\
\hline 2 day & $4.9 \%(0.5 \%-17.0 \%)$ & $1.6 \%(1.0 \%-2.6 \%)$ \\
\hline 7 day & $4.9 \%(0.5 \%-17.0 \%)$ & $2.4 \%(1.7 \%-3.5 \%)$ \\
\hline 30 day & $7.3 \%(1.8 \%-20.1 \%)$ & $3.1 \%(2.2 \%-4.6 \%)$ \\
\hline 90 day & $7.3 \%(1.8 \%-20.1 \%)$ & $3.8 \%(2.8 \%-5.1 \%)$ \\
\hline
\end{tabular}

Language disturbance can result from dysfunction of any of the following structures in the dominant hemisphere: the superior temporal gyrus, the inferior frontal gyrus and adjacent subcortical white matter, the pre- or post-central gyrus, or the thalamus. Aphasia commonly occurs after occlusion of the middle cerebral artery or one of its branches, but it has also been observed after occlusion of the posterior cerebral artery. ${ }^{15}$ Regardless of the territory involved, cardioembolism is the most common cause of language disturbance, ${ }^{15,16}$ including isolated Broca's or Wernicke's aphasia, ${ }^{7,8}$ and the relatively uncommon syndrome of global aphasia without hemiparesis. ${ }^{6} \mathrm{We}$ found that, in patients with 
persistent deficits at time of initial emergency presentation, nearly 1 in 4 patients with transient isolated aphasia had a potential cardiac source of embolism compared to 1 in 10 patients with other forms of TIA. Accordingly, isolated aphasia appears to be a strong predictor of a potential cardiac source of embolism.

Atrial fibrillation is an increasingly common cardiac arrhythmia and is the leading cause of cardioembolism to the brain. ${ }^{2}$ Oral anticoagulation therapy markedly reduces the risk of stroke, yet many patients with paroxysmal atrial fibrillation go undetected and untreated for years. ${ }^{17} \mathrm{~A}$ recent systematic review of noninvasive cardiac monitoring after stroke or TIA found that $5 \%$ of patients had previously undiagnosed atrial fibrillation. ${ }^{18}$ More recently, Sposato et al. used continuous cardiac monitoring initiated immediately after stroke or TIA to show that $13.5 \%$ of patients had previously undiagnosed atrial fibrillation. ${ }^{19}$ Similarly, Fennis et al. recently analysed the results of two large clinical trials and found that patients diagnosed with TIA and presenting with isolated aphasia were more likely to have a history of atrial fibrillation. ${ }^{20}$ The results of the present study confirm the strong association between isolated aphasia and a history of atrial fibrillation. However, we also now show that one-third of patients with isolated aphasia and a potential cardiac source of embolism did not have a known history of atrial fibrillation. The high rate of undiagnosed atrial fibrillation in patients presenting with isolated aphasia suggests that urgent screening for a potential cardiac source of embolism is warranted.

Historically, TIA has been found to have a 2-day stroke risk of $5 \%$ and a 90 -day stroke risk of approximately $10 \%$, making this presentation an important but time-sensitive opportunity for stroke prevention., ${ }^{9,10}$ The rapid initiation of antiplatelet agents and early assessment in a dedicated stroke prevention clinic can cut this risk dramatically, and both interventions were used in our cohort, ${ }^{14,21,22}$ as evidenced by a relatively low overall rate of stroke. Despite these interventions, patients with isolated aphasia in this study had double the rate of stroke at all time points assessed and a 7.3\% rate of stroke at 90 days. Although our study lacked sufficient power to demonstrate whether this clinically important difference was due to chance alone, it would not be surprising that antiplatelet agents and urgent investigation, including carotid imaging, Holter monitoring, and echocardiography would be less likely to reduce the immediate risk of stroke after TIA due to cardioembolism. Antiplatelet agents, such as aspirin, are less effective at preventing stroke caused by cardioembolism. ${ }^{23,24}$ Furthermore, ischemic strokes of cardioembolic origin have the highest rate of recurrence, ${ }^{11}$ and the same may be true for patients with TIA. Speech disturbance is a component of the $\mathrm{ABCD}^{2}$ score, a tool developed to predict the risk of stroke after TIA, ${ }^{25}$ even if an independent verification analysis has found this score to be inaccurate and nonspecific. ${ }^{12}$ It is possible that the accuracy of scoring tools may be improved by including aphasia, only when it occurs in the absence of other deficits or studying other interactions between components of the score.

The diagnosis of TIA in the present study was based upon the treating physician's discharge diagnosis in the emergency department. Some investigators have reported a false diagnosis rate of up to $60 \%$ in one U.S. study of inpatients initially assessed by an emergency physician, including those with gradual onset and nonspecific neurological symptoms. ${ }^{26}$ These results are not unexpected given the transient nature of the symptoms and the fact that many patients present at a time when their symptoms have already started to resolve. We believe that, given the specific nature of isolated aphasia, the subsequent stroke risk, and the explicit, prospective identification of neurological signs and symptoms as well as other elements of our study, the large majority of patients in our cohort had a TIA.

\section{LIMITATIONS}

This study has several limitations. First, for many patients, there was a substantial delay of at least 1 week between the index event and subsequent echocardiography and Holter monitoring. Thus, the diagnostic yield and benefits of earlier investigation for potential cardiac source of embolism immediately after the index event cannot be estimated. Moreover, only $25 \%$ and $70 \%$ of all patients received Holter monitoring or echocardiography, respectively. Accordingly, we likely underestimated the true number of patients with a potential cardiac source of embolism. Second, the definition of TIA in this study was time-based, whereas the recently revised definition is tissue-based. ${ }^{27}$ Because most patients in this study did not receive an MRI within the first 24 hours, we could not assess for acute infarction. Thus, some patients diagnosed with a TIA may be better classified as transient symptoms with infarction. $^{28}$ 


\section{CONCLUSIONS}

Cardioembolism is a leading cause of stroke, and identifying patients requiring urgent evaluation is critical. ${ }^{1}$ In this study, nearly one-quarter of all patients presenting with transient isolated aphasia had a potential cardiac source of embolism, double the rate found in patients with other forms of TIA, and persistent neurological findings at initial evaluation. Most of these patients had atrial fibrillation, and in one-third this diagnosis was new. Importantly, patients with isolated aphasia were also more likely to have a stroke in the next 90 days. Taken together, these results support the rapid evaluation and treatment of all patients with transient isolated aphasia for potential cardiac sources of embolism in order to prevent subsequent stroke.

Acknowledgements: We would like to thank the following authors for their contributions: Jason Wasserman and Jeffrey Perry conceived the idea. Jason Wasserman prepared the manuscript. Jane Sutherland coordinated the study and collected data. Mukul Sharma and Ian Stiell provided much input into the study design and revision of the manuscript. Marco Sivilotti, Marcel Émond, Andrew Worster, and Dar Dowlatshahi assisted with study design, oversaw the collection of data at their respective sites, and critically revised the manuscript.

Competing interests: The authors would like to supply their funding source: Canadian Institutes of Health Research (Grant 172524).

\section{REFERENCES}

1. Sandercock PA, Warlow CP, Jones LN, Starkey IR. Predisposing factors for cerebral infarction: the Oxfordshire community stroke project. BM7 1989;298(6666):75-80.

2. Wolf PA, Abbott RD, Kannel WB. Atrial fibrillation as an independent risk factor for stroke: the Framingham Study. Stroke 1991;22(8):983-8.

3. Bogousslavsky J, Cachin C, Regli F, et al. Cardiac sources of embolism and cerebral infarction-clinical consequences and vascular concomitants: the Lausanne Stroke Registry. Neurology 1991;41(6):855-9.

4. Kittner SJ, Sharkness CM, Sloan MA, et al. Infarcts with a cardiac source of embolism in the NINDS Stroke Data Bank: neurologic examination. Neurology 1992;42(2):299-302.

5. Hoffmann M, Sacco R, Mohr JP, Tatemichi TK. Higher cortical function deficits among acute stroke patients: the stroke data bank experience. 7 Stroke Cerebrovasc Dis 1997;6(3): 114-20.

6. Hanlon RE, Lux WE, Dromerick AW. Global aphasia without hemiparesis: language profiles and lesion distribution. 7 Neurol Neurosurg Psychiatry 1999;66(3):365-9.

7. Knepper LE, Biller J, Tranel D, et al. Etiology of stroke in patients with Wernicke's aphasia. Stroke 1989;20(12):1730-2.
8. Levine RL, Dulli DA, Dixit S, et al. Isolated Broca's area aphasia and ischemic stroke mechanism. 7 Stroke Cerebrovasc Dis 2003;12(3):127-31.

9. Gladstone DJ, Kapral MK, Fang J, et al. Management and outcomes of transient ischemic attacks in Ontario. CMAJ 2004;170(7):1099-104.

10. Johnston SC, Gress DR, Browner WS, Sidney S. Shortterm prognosis after emergency department diagnosis of TIA. FAMA 2000;284(22):2901-6.

11. Kolominsky-Rabas PL, Weber M, Gefeller O, et al. Epidemiology of ischemic stroke subtypes according to TOAST criteria: incidence, recurrence, and long-term survival in ischemic stroke subtypes: a population-based study. Stroke 2001;32(12):2735-40.

12. Perry JJ, Sharma M, Sivilotti ML, et al. Prospective validation of the ABCD2 score for patients in the emergency department with transient ischemic attack. CMA7 2011;183(10):1137-45.

13. Jones WJ, Williams LS, Meschia JF. Validating the Questionnaire for Verifying Stroke-Free Status (QVSFS) by neurological history and examination. Stroke 2001;32(10):2232-6.

14. Wasserman J, Perry J, Dowlatshahi D, et al. Stratified, urgent care for transient ischemic attack results in low stroke rates. Stroke 2010;41(11):2601-5.

15. Maulaz AB, Bezerra DC, Bogousslavsky J. Posterior cerebral artery infarction from middle cerebral artery infarction. Arch Neurol 2005;62(6):938-41.

16. Ferro JM. Cardioembolic stroke: an update. Lancet Neurol 2003;2(3):177-88.

17. Wann LS, Curtis AB, January CT, et al. 2011 ACCF/AHA/ HRS focused update on the management of patients with atrial fibrillation (updating the 2006 guideline): a report of the American College of Cardiology Foundation/American Heart Association Task Force on Practice Guidelines. Circulation 2011;123(1):104-23.

18. Liao J, Khalid Z, Scallan C, et al. Noninvasive cardiac monitoring for detecting paroxysmal atrial fibrillation or flutter after acute ischemic stroke: a systematic review. Stroke 2007;38(11):2935-40.

19. Sposato LA, Klein FR, Jauregui A, et al. Newly diagnosed atrial fibrillation after acute ischemic stroke and transient ischemic attack: importance of immediate and prolonged continuous cardiac monitoring. I Stroke Cerebrovasc Dis 2012;21(3):210-6.

20. Fennis TF, Compter A, van den Broek MW, et al. Is isolated aphasia a typical presentation of presumed cardioembolic transient ischemic attack or stroke? Cerebrovasc Dis 2013;35(4): 337-40.

21. Lavallee PC, Meseguer E, Abboud H, et al. A transient ischaemic attack clinic with round-the-clock access (SOSTIA): feasibility and effects. Lancet Neurol 2007;6(11):953-60.

22. Rothwell PM, Giles MF, Chandratheva A, et al. Effect of urgent treatment of transient ischaemic attack and minor stroke on early recurrent stroke (EXPRESS study): a prospective population-based sequential comparison. Lancet 2007;370(9596):1432-42.

23. Aguilar MI, Hart R, Pearce LA. Oral anticoagulants versus antiplatelet therapy for preventing stroke in patients with non-valvular atrial fibrillation and no history of stroke or transient ischemic attacks. Cochrane Database Syst Rev 2007;3:CD006186. 
24. Hart RG, Pearce LA, Koudstaal PJ. Transient ischemic attacks in patients with atrial fibrillation: implications for secondary prevention: the European Atrial Fibrillation Trial and Stroke Prevention in Atrial Fibrillation III Trial. Stroke 2004;35(4):948-51.

25. Johnston SC, Rothwell PM, Nguyen-Huynh MN, et al. Validation and refinement of scores to predict very early stroke risk after transient ischaemic attack. Lancet 2007; 369(9558):283-92.
26. Prabhakaran S, Silver AJ, Warrior L, et al. Misdiagnosis of transient ischemic attacks in the emergency room. Cerebrovasc Dis 2008;26(6):630-5.

27. Albers GW, Caplan LR, Easton JD, et al. Transient ischemic attack-proposal for a new definition. $N$ Engl 7 Med 2002;347(21):1713-6.

28. Ay H, Koroshetz WJ, Benner T, et al. Transient ischemic attack with infarction: a unique syndrome? Ann Neurol 2005;57(5):679-86. 